\title{
PAPEL DA MONITORIA NA FORMAÇÃO ACADÊMICA: UM RELATO DE EXPERIÊNCIA
}

Gustavo Coêlho de Oliveira, Universidade Federal de Campina Grande (UFCG), g_usta_1234@hotmail.com

Fernanda Pereira de Souza, Universidade Federal de Campina Grande (UFCG), fernandapsnutri@hotmail.com

Edineide Nunes da Silva, Universidade Federal de Campina Grande (UFCG), edineidens@hotmail.com

\section{PALAVRAS-CHAVE: Aprendizagem; Formação; Monitoria.}

\section{INTRODUÇÃO}

Ser monitor de disciplinas ofertadas no ensino superior é uma experiência de grande importância na formação acadêmica dos futuros profissionais, visto que essa prática oportuniza o desenvolvimento de habilidades intrínsecas a docência, bem como, possibilita ao discente monitor aprofundar os conhecimentos na área da monitoria e participar do processo de ensino-aprendizado dos discentes monitorados (MATOSO, 2014). Assim, a monitoria surge como uma ferramenta de apoio pedagógico oferecido os discentes interessados em aprofundar conteúdos e solucionar dificuldades nos conteúdos abordados na sala de aula, proporcionando um espaço de discussões e debates acerca das temáticas de cada disciplina (FERNANDES et al., 2015).

\section{METODOLOGIA}

Trata-se de um estudo descritivo, do tipo relato de experiência, realizado a partir das vivências de um discente-monitor de uma disciplina da grade curricular pedagógica do curso de graduação em enfermagem de uma universidade federal do alto sertão paraibano. As atividades foram desenvolvidas durante os anos de 2014 e 2015, ocasião em que foi possível aprofundar os conhecimentos e desenvolver atividades que favoreceram o processo ensinoaprendizagem junto aos discentes e docente da disciplina.

O monitor deve ter concluído a disciplina objeto da monitoria com no mínimo nota 7,0 e dispor de 12 horas semanais para o desenvolvimento das atividades, conforme critérios propostos no edital da seleção. Após o processo de seleção o discente aprovado e classificado, 
torna-se monitor da disciplina, sob supervisão e coordenação do docente e juntos planejam as atividades didático-pedagógicas voltadas à assistência direta aos discentes da disciplina.

\section{DESCRIÇÕES, RESULTADOS, INTERPRETAÇÕES...}

As atividades de monitorias realizadas objetivavam complementar os conhecimentos teóricos e práticos dos discentes da disciplina, esclarecer e tirar as dúvidas acerca dos assuntos ministrados pelo docente, além de assistir os discentes nas atividades avaliativas. Assim, a prática da monitoria contribui no processo de ensino-aprendizagem, proporcionando a qualificação do discente-monitor, o qual torna-se um agente facilitador, capaz de intensificar a relação entre os discentes matriculados na disciplina e o docente-instituição (MAGALHÃES; JANUÁRIO; MAIA, 2014; SANTOS; BATISTA, 2015).

Além disso, o programa de monitoria acadêmica possibilita o desenvolvimento da autonomia do discente-monitor, com o aumento do senso de responsabilidade e ampliação do vínculo do discente-monitor-docente. Portanto, essa prática é de extrema importância para o amadurecimento social e acadêmico, com o aprendizado dos discentes para com a disciplina e solidificação dos conhecimentos adquiridos anteriormente com atividades que proporcionam uma base teórico/prática que são apresentadas para o desenvolvimento acadêmico e profissional, pois é uma atividade onde integra os discentes na busca de conhecimentos proporcionando a troca de informações (CARVALHO et al., 2014; JESUS et al., 2012).

Como as experiências em monitoria, o monitor consolida as noções de aprendizado, responsabilidades, compromisso e dedicação que são fundamentais para a formação acadêmica. Logo, a monitoria é realizada em prol da melhoria no aprendizado dos discentes como mecanismo fundamental para apropriação dos conteúdos apresentados na disciplina, possibilitando a ampliação dos conhecimentos tanto dos discentes quanto do monitor com auxílio extraclasse (MATOSO, 2014).

Outrossim, o programa possibilita o enriquecimento acadêmico na área da disciplina além de fomentar o interesse pela carreira docente do discente-monitor, pois o desenvolvimento das atividades viabilizam habilidades e técnicas do profissional docente.

\section{CONSIDERAÇÕES FINAIS}

Evidencia-se que a prática da monitoria nos cursos de graduação demonstram aspectos positivos para o discente-monitor, bem como, para o docente-supervisor e discentes 
monitorados, pois possibilitam momentos de aprimoramento e edificação dos conhecimentos teórico-práticos. Portanto, a experiência de monitor é essencial na formação acadêmica e profissional, o que solidifica a construção de um processo de ensino-aprendizado de qualidade.

\section{REFERÊNCIAS}

CARVALHO, I. S et al. A. Monitoria em semiologia e semiotécnica para a enfermagem: um relato de experiência. Revista de Enfermagem da UFSM, v.2, n.2, mai./ago., 2012.

FERNANDES, N. C. et al. Monitoria acadêmica e o cuidado da pessoa com estomia: relato de experiência. Revista Mineira de Enfermagem, Belo Horizonte, v.19, n. 2, p.238-241, 2015.

JESUS, D. M. O. et al. E. Programas de monitorias: um estudo de caso em uma IFES. Revista Pensamento Contemporâneo em Administração, Rio de Janeiro, v.6, n.4, out./dez., 2012.

MAGALHÃES, L.D.; JANUÁRIO, I.J.; MAIA, A.K.F. A monitoria acadêmica da disciplina de cuidados críticos para a enfermagem: um relato de experiência. Revista da Universidade Vale do Rio Verde, Minas Gerais. v.12, n.2, p.556-565, 2014.

MATOSO, L.M.L.; A importância da monitoria na formação acadêmica do monitor: um relato de experiência. Revista Científica da Escola da Saúde, Natal, a.3, n.2, p.77-83, abr./set., 2014.

SANTOS, G. M.; BATISTA, S. H. S. S. Monitoria acadêmica em formação em/para saúde: desafios e possibilidades no âmbito de um currículo interprofissional em saúde. ABCS Health Sciences, São Paulo, v.40, n.3, p.203-207, 2015. 